\title{
Therapeutic management of macrodontic tooth
}

\author{
Marzena PuceK ${ }^{1}$, Dominika Grabowska-MiazeK ${ }^{1}$, Jolanta Szymanska ${ }^{2 \star}$ \\ ${ }^{1}$ Beautiful Smile Clinic, Lublin, Poland \\ ${ }^{2}$ Chair and Department of Paedodontics, Medical University of Lublin, Poland
}

\begin{tabular}{ll}
\hline ARTICLE INFO & ABSTRACT \\
\cline { 1 - 2 } $\begin{array}{l}\text { Received 01 July 2014 } \\
\text { Accepted 15 July 2014 }\end{array}$ & $\begin{array}{l}\text { Macrodontic tooth (in Latin: macrodens) is an anomaly of the structure of a tooth; it } \\
\text { usually refers to the medial upper incisors, and is usually the cause of malocclusion } \\
\text { in the anterior jaw. The aim of this study was to assess the effectiveness of therapeutic } \\
\text { Keywords: }\end{array}$ \\
$\begin{array}{l}\text { mantal anomalies, } \\
\text { macrodontic tooth, } \\
\text { orthodontic treatment. }\end{array}$ & $\begin{array}{l}\text { and endodontic treatment of the macrodontic tooth was applied to dental defects } \\
\text { resulting from the presence of a macrodontic tooth. Determining precise objectives and } \\
\text { their implementation in collaboration with the patient makes obtaining satisfactory } \\
\text { functional and aesthetic effect possible. }\end{array}$
\end{tabular}

\section{INTRODUCTION}

Macrodontic tooth (in Latin: macrodens) is an anomaly of the structure of the tooth; most often it relates to medial upper incisors, and the development of this anomaly is attributed to dental lamina hyperactivity and organo-developmental disorders in the first pharyngeal arch. It is usually the cause of malocclusion in the anterior jaw $[2,4]$.

\section{AIM}

The aim of this study was to assess the effectiveness of therapeutic management of a macrodontic tooth.

\section{MATERIAL AND METHODS}

Integrated treatment of a patient aged 24 years and 4 months with macrodontic tooth (tooth 11) was performed at the Beautiful Smile Clinic in Lublin, Poland. The case history showed that the man had referred to the dentist due to aesthetic and functional discomfort of masticatory system. He informed about the previous orthodontic consultations, which necessitated extraction of teeth, to which he had not agreed. The extra-oral examination confirmed visible extension of sub-nasal area. The intra-oral examination confirmed anterior cross bite around maxillary lateral incisor on the left side with the partial absence of space for the tooth, and the total lack of space for incisor on the right side. Narrowing of the jaw and tongue dysfunction was found, the cause of which was a Gothic palate limiting the amount of space

Corresponding author

e-mail: szymanska.lublin@gmail.com for the tongue and preventing its proper position during articulation. The upper dental arch represented the letter $\mathrm{V}$ in shape, which influenced an analogous shape of the bottom arch. The attention was drawn to tooth 11, due to its shape, color, and first of all - its size. Its width, measuring $14 \mathrm{~mm}$ differed greatly from the width of the tooth 21 , which was $9.5 \mathrm{~mm}$. Bruising around the neck of the tooth 11 was visible, which significantly disrupted the white-andred aesthetics. Additionally, numerous dental irregularities were found, irregularity of midline - shifting of the upper line to the right and the lower - to the left side. The lower dental arch was characterized by irregularities - pathological wearing-off of the incisal edges of all incisors, lack of tooth 36 and 45, and the teeth 37 and 46 present in the arch were inclined mesially toward the gaps resulting from the loss of adjacent teeth. Based on the analysis of diagnostic models, there was specified class II, division 2 according to Angle's classification and cuspid class II. The width of palate by McNamara was $35 \mathrm{~mm}$. In addition, the panoramic radiographic images showed that the teeth 11, 16, 26, 47 had been treated endodontically. Based on cephalometric analysis, the face type with the vertical high-angular relationship of the skull and jaw bases was confirmed (Fig. 1, 2, 3).

The patient was suggested a treatment implying simultaneous implementation of thick-arch expander of Quad Helix type to expand the upper dental arch and eliminate cross bite on teeth 12 and 22 (total lack of space for the tooth 12 and partial for the tooth 22) with involvement of these teeth and the upper thin-arch appliance and lower biting splint [3]. In the following stage of treatment, after 4 months, fixed braces were applied. This procedure was aimed at simultaneous, coordinated widening of upper and lower arch, to obtain a symmetrical position of the mandible. Such a treatment plan 


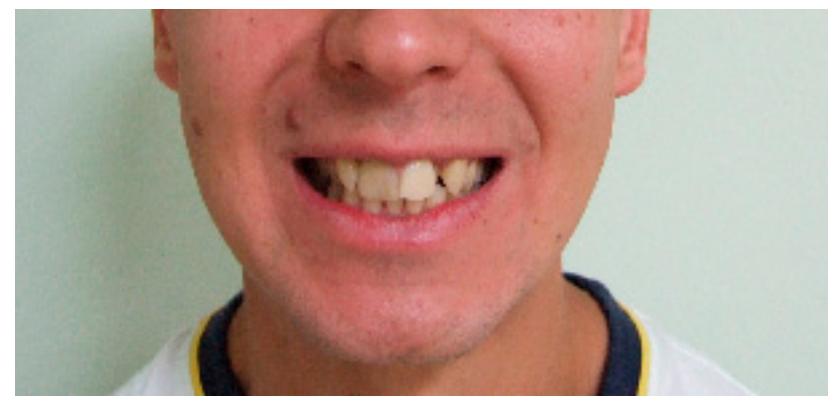

Figure 1. External view of the patient's teeth before treatment procedure
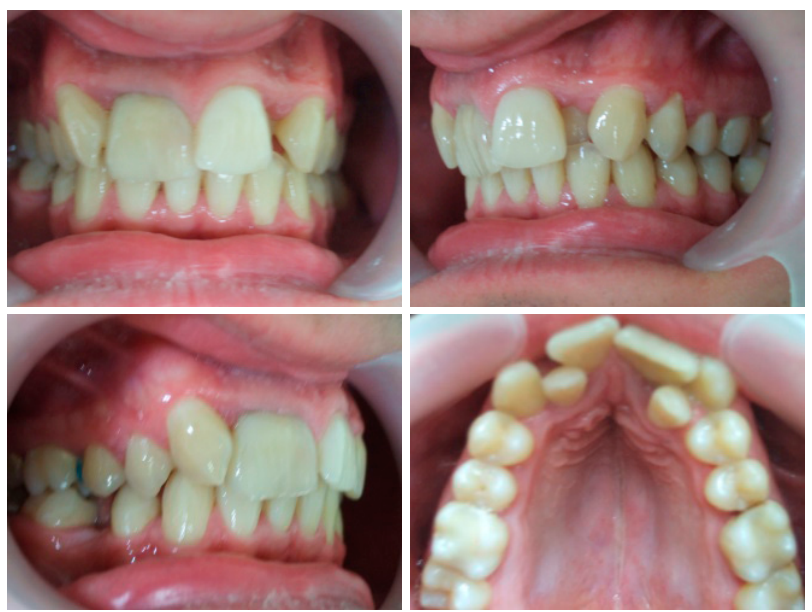

Figure 2. Intraoral view of patient's teeth before treatment procedure

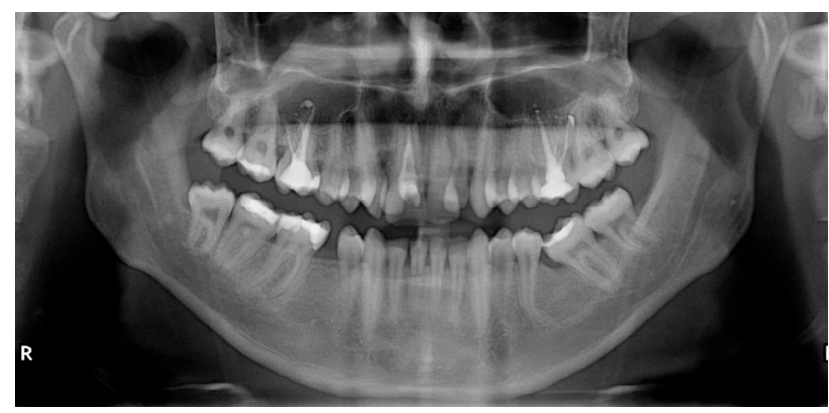

Figure 3. Panoramic radiographic image before treatment procedure

took into account alignment of the teeth involving palatallocated teeth 12 and 22, obtaining correct relationships of teeth in the opposing arches, a symmetrical functional position of the mandible and obtaining correct relationship of vertical and horizontal biting. In the next step, it assumed the aesthetic reconstruction of tooth crown 11 and 21 with the repeated endodontic treatment of the tooth 11. After the active treatment phase, retention was scheduled in the form of upper and lower plate and the use of fixed retainers to both the upper and lower arches $[5,6]$.

\section{RESULTS}

In the initial stage, a widening of the upper dental arch was achieved along with simultaneous alignment of the teeth by using the upper and sequentially lower permanent braces with reconstruction of the missing space for the teeth 12 and 22 . The activation period and the period of retention with the use of Quad Helix apparatus was 4 months. The upper permanent braces and lower bracket system MBT 0.022 ”

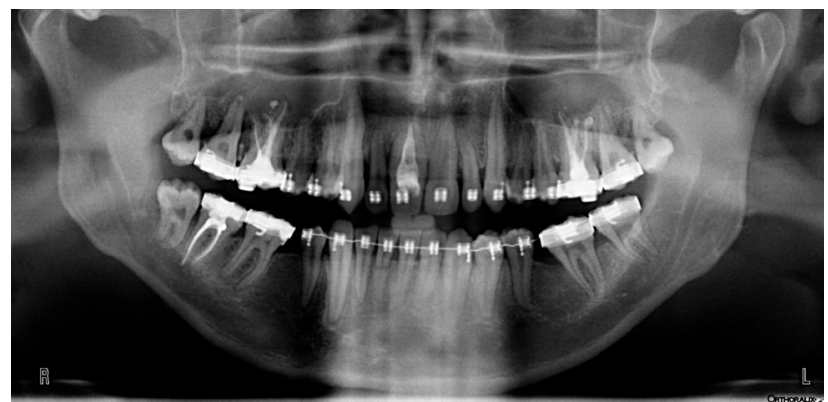

Figure 4. Panoramic radiographic image during treatment procedure
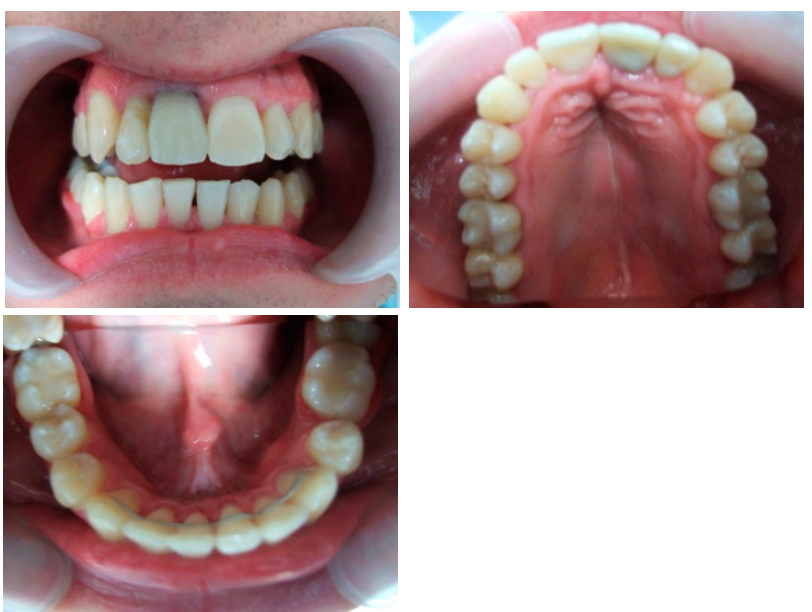

Figure 5. Intraoral view of patient's teeth after treatment procedure

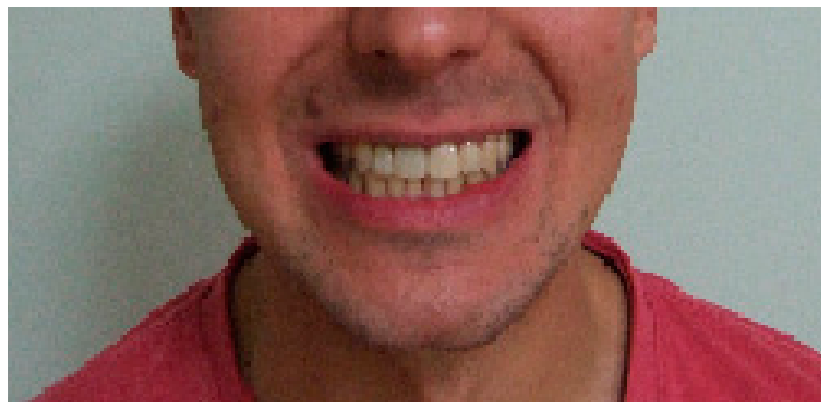

Figure 6. Internal view of patient's teeth after treatment procedure

were used. In the initial treatment phase, there were applied arches NiTi $0.014,0.016,0.016 \times 0.016,0.016 \times 0.022$, followed by steel arches $0.016,0.016 \times 0.016,0.016 \times 0.022$. During treatment, there were used intermaxillary orthodontic appliances in order to improve occlusion. The gaps after missing teeth in the lower arch were closed and the midline of the upper and lower arch and stripping of tooth 11, were aligned, which allowed for obtaining symmetry and harmony in the upper arch and the aesthetics of a smile. The duration of treatment with permanent braces was 2 years and 5 months. The applied retention appliances were the upper and lower plates and a permanent retention concerned section 13-23 of the upper arch and in 33-43 of the lower arch (Fig. 4).

\section{DISCUSSION}

Orthodontic treatment aims at restoring correct occlusion and chewing function and improving the aesthetics of the dentition and facial esthetics of the patient. All 
planned objectives were achieved in the applied treatment. The proper relationship of the teeth - Class I according to Angle's classification and cuspid class I as well as alignment of the symmetry line of the upper and lower arch, were obtained. The most important for the patient was primarily the aesthetic effect - resulting improvement in dental aesthetics, smile and facial aesthetics. Subsequently - restoration of the occlusion and normal masticatory function was achieved (Fig. 5, 6) [1].

\section{CONCLUSIONS}

In conclusion, the treatment of a patient with malocclusion, with concomitant impaired function of the masticatory system caused by this defect, obliges the doctor to clarify the objectives precisely and implement them consistently [7]. The therapeutic treatment should be planned accordingly, taking into account local conditions in the patient's mouth, as well as the possibilities and therapeutic skills of the doctor or the therapeutic team. It is necessary to take into account the patient's expectations - the aesthetic and functional ones, as well as patient's financial capabilities. The therapeutic procedure should be carried out in close collaboration with the patient.

\section{REFERENCES}

1. Birkeland K., Boe O., Wisth P.J.: Relationship between occlusion and satisfaction with dental appearance in orthodontically treated and untreated groups. A longitudinal study. Eur. J. Orthod., 509, 22, 2000.

2. Komorowska A., Dunin-Wilczyńska I., Munir T.: Zlanie, rozszczepienie i makrodoncja górnych siekaczy przyśrodkowych. Ort. Współcz., 93, $5,2003$.

3. Łoboda M.: Aparaty grubołukowe i ich zastosowanie w praktyce ortodontycznej. Poradnik Stomatologiczny 279, 10, 2010.

4. Szpringer-Nodzak M., Wochna-Sobańska M.: Stomatologia wieku rozwojowego. ed. PZWL, Warszawa 2004.

5. Proffit W.R., Fields Jr H.W., Sarver D.M.: Ortodoncja wspótczesna. Tom I, wyd. I polskie, red. A. Komorowska. Elservier Urban \& Partner, Wrocław 2009.

6. Proffit W.R., Fields Jr H.W., Sarver D.M.: Ortodoncja współczesna. Tom II, wyd. I polskie, red. A. Komorowska. Elservier Urban \& Partner, Wrocław 2010.

7. Wojtasińska-Chebel P., Dawiec M.: Współpraca periodontologiczna na różnych etapach leczenia ortodontycznego. Poradnik Stomatologiczny $274,10,2010$. 